\title{
A Comparison of Noninternalizing (Herkinorin) and Internalizing (DAMGO) $\mu$-Opioid Agonists on Cellular Markers Related to Opioid Tolerance and Dependence
}

\author{
HENG XU, ${ }^{1}$ JOHN S. PARTILLA, ${ }^{1}$ XIAOYING WANG,${ }^{1}$ JOHN M. RUTHERFORD, ${ }^{1}$ KEVIN TIDGEWELL, ${ }^{2}$ \\ THOMAS E. PRISINZANO,$^{2}$ LAURA M. BOHN, ${ }^{3,4}$ AND RICHARD B. ROTHMAN ${ }^{1 *}$ \\ ${ }^{1}$ Clinical Psychopharmacology Section, Intramural Research Program, National Institute on Drug Abuse, \\ National Institutes of Health, DHHS, Baltimore, Maryland \\ ${ }^{2}$ Division of Medicinal and Natural Products Chemistry, College of Pharmacy, \\ University of Iowa, Iowa City, Iowa \\ ${ }^{3}$ Department of Pharmacology, Ohio State University College of Medicine and Public Health, Columbus, Ohio \\ ${ }^{4}$ Department of Psychiatry, Ohio State University College of Medicine and Public Health, Columbus, Ohio
}

\begin{abstract}
KEY WORDS DAMGO; herkinorin; tolerance; dependence; G proteins
ABSTRACT Previous studies established that Tyr-D-Ala-Gly-N-Me-Phe-Gly-ol (DAMGO) and (2S,4aR,6aR,7R,9S,10aS,10bR)-9-(Benzoyloxy)-2-(3-furanyl)dodecahydro-6a,10b-dimethyl-4,10-dioxo-2H-naphtho-[2,1-c]pyran-7-carboxylic acid methyl ester (herkinorin) are fully efficacious $\mu$-agonists. Herkinorin (HERK), unlike DAMGO, does not recruit $\beta$-arrestin and promote $\mu$-receptor internalization, even in cells that over express $\beta$-arrestin. We hypothesized that chronic HERK and DAMGO treatment will differentially affect cellular markers of tolerance and dependence. CHO cells expressing the cloned human $\mu$-receptor were treated for $20 \mathrm{~h}$ with $10 \mu \mathrm{M}$ DAMGO, HERK, morphine, or medium. Both DAMGO and HERK acted as full agonists in the $\left[{ }^{35} \mathrm{~S}\right]-$ GTP- $\gamma-\mathrm{S}$ binding assay with $E_{\mathrm{MAX}}$ values of $230 \%$ and $\mathrm{EC}_{50}$ values of 12.8 and $92.5 \mathrm{nM}$, respectively. In the cAMP assay, DAMGO and HERK had similar $E_{\text {MAX }}$ values of $\sim 80 \%$ and $\mathrm{EC}_{50}$ values of 3.23 and $48.7 \mathrm{nM}$, respectively. Chronic exposure to both drugs produced moderate tolerance to both drugs ( $\sim 2$ to 5 fold $)$ in the $\left[{ }^{35} \mathrm{~S}\right] \mathrm{GTP}-\gamma-\mathrm{S}$ binding assay. In the cAMP assay, chronic DAMGO produced tolerance to both drugs ( $\sim 3$ to 4 fold). Chronic HERK eliminated the ability of either drug to inhibit forskolin-stimulated cAMP accumulation. Chronic DAMGO increased, and chronic HERK decreased, forskolin-stimulated cAMP accumulation. Naloxone, after chronic HERK (but not DAMGO) induced a large increase in forskolin-stimulated cAMP accumulation. Viewed collectively with published data, the current data indicate that both internalizing and noninternalizing $\mu$-agonists produce cellular signs of tolerance and dependence. Synapse 61:166-175, 2007. Published 2006 Wiley-Liss, Inc. ${ }^{\dagger}$
\end{abstract}

\section{INTRODUCTION}

Opioid $\mu$-receptors are coupled primarily to $\mathrm{G}$ proteins of the $G_{i} / G_{o}$ family and modulate the function of effector molecules, such as adenylate cyclase and protein kinases (Bohn et al., 2000; Standifer and Pasternak, 1997; Williams et al., 2001). Continual exposure of $\mu$-opioid receptor to $\mu$-agonists produces tolerance and dependence. The mechanisms underlying the development of opioid tolerance and dependence are complex, and not fully elucidated (Nestler and Aghajanian, 1997; Williams et al., 2001). At the cellular level, chronic treatment with opioid agonists can induce a diverse range of cellular adaptations. These include changes in the expression and function of the opioid receptors and the various proteins of the signal transduction pathways that mediate opioid effects,

\footnotetext{
Contract grant sponsor: NIH (Intramural Research Program); Contract gran sponsor: National Institute on Drug Abuse; Contract grant numbers: R01 DA018151-01A2, R01 DA12970.

*Correspondence to: Richard B. Rothman, M.D., Ph.D., Clinical Psychopharmacology Section, IRP, NIDA, NIH, P.O. Box 5180, 5500 Nathan Shock Drive, Baltimore, MD 21224, USA. E-mail: rrothman@mail.nih.gov

Received 8 June 2006; Accepted 29 October 2006

DOI 10.1002/syn.20356

Published online in Wiley InterScience (www.interscience.wiley.com).
} 
including $\mathrm{G}$ proteins, adenylyl cyclase, protein kinases (Gintzler and Chakrabarti, 2000; Law et al., 2004; Nestler and Aghajanian, 1997; Waldhoer et al., 2004) and the expression and function of cytoskeletal proteins (Xu et al., 2005). In addition, chronic morphine also produces a number of system-level adaptations (Williams et al., 2001), including increased activity by antiopioid peptides in rat brain rendered tolerant to morphine (Rothman, 1992; Simonin et al., 2006).

Receptor desensitization, phosphorylation, and endocytosis are critical molecular mechanisms contributing to the development of opioid tolerance and dependence (Finn and Whistler, 2001; Waldhoer et al., 2004). Data published by the Whistler group, for example, indicates that $\mu$-agonists that promote receptor internalization produce lower degrees of cAMP superactivation. This cellular adaptation, detected as chronic-agonist induced increases in forskolin-stimulated cAMP accumulation, is generally accepted as a cellular marker for opioid withdrawal [for review see: (Nestler and Aghajanian, 1997; Wang et al., 2003)]. On the other hand, Koch et al. (2005) concluded that $\mu$-agonists that promote receptor endocytosis counteract receptor desensitization and the development of tolerance, but facilitate cAMP superactivation. In support of these findings, Zhao et al. (2006) reported that the ability of a $\mu$-agonist to produce cAMP superactivation is independent of receptor internalization.

In light of these divergent findings, we decided to further investigate the effect of internalizing and noninternalizing $\mu$-agonists on cellular markers of tolerance and dependence. Towards this end, we compared the pharmacological effects of DAMGO (Tyr-D-AlaGly-N-Me-Phe-Gly-ol), an agonist that strongly internalizes $\mu$-receptors, and herkinorin (HERK) $((2 S, 4 \mathrm{a} R$,$6 \mathrm{a} R, 7 R, 9 S, 10 \mathrm{a} S, 10 \mathrm{~b} R$ )-9-(Benzoyloxy)-2-(3-furanyl)dodecahydro-6a,10b-dimethyl-4,10-dioxo- $2 H$-naphtho-[2,1-c]pyran-7-carboxylic acid methyl ester), a nonnitrogenous neoclerodane diterpene fully efficacious $\mu$-agonist (Harding et al., 2005). Unlike DAMGO, HERK does not promote $\beta$-arrestin recruitment and $\mu$-receptor internalization, even in cells that over express $\beta$-arrestin and the GPCR kinase, GRK2, (Groer et al., 2006). Receptor desensitization and opioid tolerance were assessed by agonist stimulation of $\left[{ }^{35} \mathrm{~S}\right] \mathrm{GTP}-\gamma-\mathrm{S}$ binding and agonist-mediated inhibition of forskolin-stimulated cAMP

Abbreviations

CHO cells hMOR-CHO

DAMGO

Herkinorin

$\left[{ }^{35} \mathrm{~S}\right] \mathrm{GTP}-\gamma-\mathrm{S}$ cAMP

CTAP chinese hamster ovary cells

CHO cells expressing the cloned human $\mu$-opioid receptor

Tyr-D-Ala-Gly-N-Me-Phe-Gly-ol

$(2 S, 4 \mathrm{a} R, 6 \mathrm{a} R, 7 R, 9 S, 10 \mathrm{a} S, 10 \mathrm{~b} R)-9$-(Benzoyloxy)-2-(3furanyl)dodecahydro-6a,10b-dimethyl-4,10-dioxo- $2 \mathrm{H}$ naphtho-[2,1-c]pyran-7-carboxylic Acid Methyl Ester guanosine $5^{\prime}-O-\left(3-\left[{ }^{35} \mathrm{~S}\right]\right.$ thio)triphosphate

adenosine $3^{\prime}, 5^{\prime}$-cyclic monophosphate

D-Phe-Cys-Tyr-D-Trp-Arg-Thr-Pen-Thr- $\mathrm{NH}_{2}$ accumulation. Dependence was determined by measuring the magnitude of forskolin-stimulated cAMP accumulation. The presence of constitutively active receptor was assessed by measuring the basal $\left[{ }^{35} \mathrm{~S}\right] \mathrm{GTP}-$ $\gamma-\mathrm{S}$ binding and the direct effect of naloxone on forskolin-stimulated cAMP accumulation in agonist-pretreated cells. Our data indicate that both internalizing and noninternalizing $\mu$-agonists produce cellular signs of tolerance and dependence in hMOR-CHO cells after chronic treatment and that this effect was associated with the development of cAMP superactivation.

\section{Cell culture and membrane preparation}

The recombinant $\mathrm{CHO}$ cells (hMOR-CHO) were produced by stable transfection with the human $\mu$-opioid receptor cDNA, and provided by Dr. L. Toll (SRI International, CA). The cells were grown on plastic flasks in DMEM/ F-12 (50/50\%) medium containing $10 \%$ FBS, 100 units $/ \mathrm{mL}$ penicillin, $100 \mu \mathrm{g} / \mathrm{mL}$ streptomycin, and G-418 (0.20-0.25 mg/mL) under 95\% air/ $5 \% \mathrm{CO}_{2}$ at $37^{\circ} \mathrm{C}$. Cell monolayers were harvested and homogenized by sonication in $50 \mathrm{mM}$ Tris-HCl, $\mathrm{pH} 7.4$, containing $4 \mu \mathrm{g} / \mathrm{mL}$ leupeptin, $2 \mu \mathrm{g} / \mathrm{mL}$ chymostatin, $10 \mu \mathrm{g} / \mathrm{mL}$ bestatin, and $100 \mu \mathrm{g} / \mathrm{mL}$ bacitracin. The homogenate was centrifuged at $15,000 \mathrm{rpm}$ for $10 \mathrm{~min}$ at $4{ }^{\circ} \mathrm{C}$, and the supernatant discarded. The membrane pellets were resuspended in binding buffer and used for $\left[{ }^{35} \mathrm{~S}\right] \mathrm{GTP}-\gamma-\mathrm{S}$ binding assays.

For drug pretreatment experiments, cells were incubated in fresh medium with $10 \mu \mathrm{M}$ drug (morphine, DAMGO, or HERK) for $20 \mathrm{~h}$. Cells were washed three times with phosphate-buffered saline (PBS), and processed for various assays. This treatment produces opioid tolerance to morphine (Xu et al., 2003). Thus, in these experiments, we are reporting the effects of chronic drug exposure shortly after the withdrawal of the drug. Future experiments will be needed to determine the effect of the $20 \mathrm{~h}$ drug exposure at time points further removed from agonist removal.

\section{$\left[{ }^{35} \mathbf{S}\right]-$ GTP- $\gamma-S$ binding assays}

$\left[{ }^{35} \mathrm{~S}\right]-\mathrm{GTP}-\gamma-\mathrm{S}$ binding was determined as described previously ( $\mathrm{Xu}$ et al., 2001). Briefly, test tubes received the following additions: $50 \mu \mathrm{L}$ buffer A (50 mM Tris$\mathrm{HCl}, \mathrm{pH} 7.4$, containing $100 \mathrm{mM} \mathrm{NaCl}, 10 \mathrm{mM} \mathrm{MgCl}$, $1 \mathrm{mM}$ EDTA), $50 \mu \mathrm{L}$ GDP in buffer A (final concentration $=50 \mu \mathrm{M}), 50 \mu \mathrm{L}$ drug in buffer $\mathrm{A} / 0.1 \% \mathrm{BSA}$, $50 \mu \mathrm{L}\left[{ }^{35} \mathrm{~S}\right]-\mathrm{GTP}-\gamma-\mathrm{S}$ in buffer A (final concentration = $50 \mathrm{pM}$ ), and $300 \mu \mathrm{L}$ of cell membranes $(50 \mu \mathrm{g}$ of protein) in buffer B (50 mM Tris- $\mathrm{HCl}, \mathrm{pH} 7.4$, containing $100 \mathrm{mM} \mathrm{NaCl}, 10 \mathrm{mM} \mathrm{MgCl} 2,1 \mathrm{mM}$ EDTA, $1.67 \mathrm{mM}$ DTT, $0.15 \%$ BSA). The final concentrations of reagents in the $\left[{ }^{35} \mathrm{~S}\right]-\mathrm{GTP}-\gamma-\mathrm{S}$ binding assays were: $50 \mathrm{mM}$ Tris$\mathrm{HCl}$, pH 7.4, containing $100 \mathrm{mM} \mathrm{NaCl}, 10 \mathrm{mM} \mathrm{MgCl}$, $1 \mathrm{mM}$ EDTA, $1 \mathrm{mM}$ DTT, and 0.1\% BSA. Incubations 
proceeded for $2 \mathrm{~h}$ at $25^{\circ} \mathrm{C}$ (steady state). Nonspecific binding was determined using GTP- $\gamma-\mathrm{S}(40 \mu \mathrm{M})$. Bound and free $\left[{ }^{35} \mathrm{~S}\right]-\mathrm{GTP}-\gamma-\mathrm{S}$ were separated by vacuum filtration through $\mathrm{GF} / \mathrm{B}$ filters. The filters were punched into the vials to which was added $0.6 \mathrm{~mL}$ LSC-cocktail (CytoScint) and counted in a liquid scintillation counter at $60 \%$ efficiency.

As previously described (Xu et al., 2004), the percent stimulation of $\left[{ }^{35} \mathrm{~S}\right]-\mathrm{GTP}-\gamma-\mathrm{S}$ binding was calculated according to the following formula: $(\mathrm{S}-\mathrm{B}) / \mathrm{B} \times$ 100 , where $B$ is the basal level of $\left[{ }^{35} \mathrm{~S}\right]-\mathrm{GTP}-\gamma-\mathrm{S}$ binding and $S$ is the stimulated level of $\left[{ }^{35} \mathrm{~S}\right]-\mathrm{GTP}-\gamma-\mathrm{S}$ binding. The data of three experiments were pooled and fit to a dose-response equation for the $\mathrm{EC}_{50}$ values (the concentration that produces $50 \%$ maximal stimulation of $\left[{ }^{35} \mathrm{~S}\right]-\mathrm{GTP}-\gamma-\mathrm{S}$ binding) and $E_{\mathrm{MAX}}$ (\% of maximal stimulation in the $\left[{ }^{35} \mathrm{~S}\right]-\mathrm{GTP}-\gamma-\mathrm{S}$ binding) using the program MLAB-PC (Civilized Software, Bethesda, MD).

Statistical significance between the $\mathrm{EC}_{50}$ and $E_{\mathrm{MAX}}$ values of the control and drug-treated data sets were determined by simultaneously fitting the data first with these parameters unconstrained and then a second time with the parameters constrained to be the same values. The $F$-test was used to determine the corresponding $P$-values for the increase in the sum of squares that resulted from the constraint. This procedure is described in detail elsewhere (Rothman et al., 1991).

\section{Binding surface analysis of $\left[{ }^{35} \mathrm{~S}\right]-\mathrm{GTP}-\gamma-\mathrm{S}$ binding parameters}

Binding surfaces were generated using published procedures (Rothman et al., 1991). Briefly, two concentrations of $\left[{ }^{35} \mathrm{~S}\right]-\mathrm{GTP}-\gamma-\mathrm{S}(0.1$ and $1 \mathrm{nM})$ were each displaced by nine concentrations of GTP- $\gamma-\mathrm{S}$ (in the absence and presence of opioid agonist (10 $\mu \mathrm{M}$ DAMGO). Each surface generated 20 data points. Two final data sets (control and DAMGO or HERK-treated cells) were created from three independent experiments, each composed of 120 data points. As found in previous studies (Heyliger et al., 2000; Xu et al., 2003), using MLAB$\mathrm{PC},\left[{ }^{35} \mathrm{~S}\right]-\mathrm{GTP}-\gamma-\mathrm{S}$ binding fit a two site binding model, and opioid agonists significantly affected the high, but not the low affinity binding site. We fit the control and DAMGO-stimulated data sets to a two site binding model first, with the low affinity binding parameters constrained to be the same, to determine the best-fit estimates of the $K_{\mathrm{d}}$ and $B_{\mathrm{MAX}}$ values of the high affinity $\left[{ }^{35} \mathrm{~S}\right]-\mathrm{GTP}-\gamma-\mathrm{S}$ binding site. Statistical significance between the high-affinity $K_{\mathrm{d}}$ and $B_{\mathrm{MAX}}$ values of the control and DAMGO-stimulated data sets were determined by simultaneously fitting the data first with these parameters unconstrained and then a second time with the parameters constrained to be the same values. We report parameter values $\pm \mathrm{SD}$. The $F$-test was used to determine the corresponding $P$-values for the increase in the sum of squares that resulted from the constraint. This procedure is described in detail elsewhere (Rothman et al., 1991).

\section{Cyclic AMP assays}

Functional coupling of the cloned $\mu$-opioid receptor to adenylate cyclase was determined by measuring changes in the levels of cellular cAMP. The assay procedures followed the protocol provided by Molecular Devices, CatchPoint Cyclic-AMP Fluorecent Assay Kit (a horseradish-peroxidase based competitive immunoassay kit). Briefly, cells were grown to $80 \%$ confluence in 96 well black-walled, clear bottom plates (Corning, Corning, NY) that had been treated with poly-l-lysine $(50 \mu \mathrm{g} / \mathrm{mL})$. After treatment with medium or $10 \mu \mathrm{M}$ drug for $20 \mathrm{~h}$, cells were rinsed three times with 300 $\mu \mathrm{L} /$ well Krebs-Ringer Bicarbonate buffer (KRBG, $\mathrm{pH}$ 7.4). KRBG containing $0.75 \mathrm{mM}$ 3-isobutyl-1-methylxanthine and $1 \mathrm{mg} / \mathrm{mL}$ bovine serum albumin (KIB) and appropriate agonists and antagonists were added to each well $(90 \mu \mathrm{L})$. After $30 \mathrm{~min}$ incubation at $37^{\circ} \mathrm{C}$, $100 \mu \mathrm{M}$ forskolin in KIB was added to each well in a volume of $10 \mu \mathrm{L}$. Cyclic AMP production was terminated $40 \mathrm{~min}$ later by the addition of $50 \mu \mathrm{L}$ of a cell lysing solution (Molecular Devices, Sunnyvale, CA). This assay was sensitive between 0.1 and 10 pmoles cAMP in a $40 \mu \mathrm{L}$ sample volume. A FlexStation II (Molecular Devices) was used to read and quantitate fluorescence intensity of the plate. Data from three independent experiments were analyzed using the program GraphPad Prism Version 3 (GraphPad Software, San Diego, CA) for the $\mathrm{EC}_{50}$ (the concentration of agonist that produces fifty percent inhibition of forskolin stimulated cAMP accumulation) and $E_{\mathrm{MAX}}(\%$ of maximal inhibition of forskolin-stimulated cAMP). The amount of cAMP in the samples was quantitated against a cAMP standard curve. Forskolin $(100 \mu \mathrm{M})$ stimulated cAMP formation in the absence of agonist was defined as $100 \%$. Results are reported as the mean \pm SEM. Statistical significance was determined using the Student's $t$-test.

\section{Western blotting of $\mu$-opioid receptor and G protein $\alpha$-subunits}

After treatment with medium or $10 \mu \mathrm{M}$ drug for 20 $\mathrm{h}$, cells were rinsed three times with PBS. Cell monolayers were harvested and homogenized by sonication in RIPA Lysis Buffer (s.c.-24,948, Santa Cruz Biotechnology). Protein concentration was determined using the Pierce BCA Protein Assay Reagent Kit (Rockford, IL). Homogenates were diluted to a desired protein concentration with $2 \times$ SDS-PAGE loading buffer (Invitrogen, Carlsbad, CA). Samples were boiled for $6 \mathrm{~min}$, and loaded into 8-16\% polyacrylamide mini- 
gels (Invitrogen) for gel electrophoresis at $30 \mu \mathrm{g} / \mathrm{lane}$. Proteins from gel are transferred to Immobilon-PVDF membranes (Millipore, Bedford, MA) using a semidry apparatus (Bio-Rad, Hercules, CA). Nonspecific binding to membranes was prevented by blocking for 60 min at room temperature with PBS solution containing 5\% nonfat dry milk. Membranes were then probed by overnight incubation $\left(4^{\circ} \mathrm{C}\right)$ with $1: 1000$ dilution of rabbit polyclonal anti-G protein $\alpha$-subunits antibodies (Calbiochem, LA jolla, CA) or 1:2000 dilution of rabbit polyclonal antiopioid $\mu$-receptor antibody (Calbiochem, San Diego, CA) with PBS solution containing $0.25 \%$ nonfat dry milk. Membranes were washed for three times (10 $\min \times 3$ in TBS solution), and then incubated with 1:5000 dilution of horseradish peroxidase conjugate secondary antibody in PBS solution, containing $0.25 \%$ nonfat dry milk for $90 \mathrm{~min}$ at room temperature. After washing three more times, antibody complex was visualized by chemiluminescence using a kit from Pierce Biotechnology (Rockford, IL). Western blots were digitized and quantified using densitometric analysis (NIH Image software). Samples obtained from three independent experiments were pooled and three separate Western blots were run on each pooled sample. Data from the three Western blots were analyzed using the program GraphPad Prism Version 3. Results are presented as the mean \pm SEM. Statistical significance was determined using the Student's $t$-test.

\section{Sources}

$\left[{ }^{35} \mathrm{~S}\right] \mathrm{GTP}-\gamma-\mathrm{S}(\mathrm{SA}=1250 \mathrm{Ci} / \mathrm{mmol})$ was obtained from DuPont NEN (Boston, MA). DAMGO and D-PheCys-Tyr-D-Trp-Arg-Thr-Pen-Thr-NH $\mathrm{N}_{2}$ (CTAP) were provided by Multiple Peptide System via the Research Technology Branch, NIDA. HERK was synthesized as described previously (Harding et al., 2005). The KrebsRinger Bicarbonate Buffer (product K4002), GTP- $\gamma-\mathrm{S}$, GDP, forskolin, and cAMP were obtained from Sigma Chemical (St. Louis, MO), and CatchPoint Cyclic-AMP Fluorescent Assay Kit (R8088) from Molecular Devices (Sunnyvale, CA). For Western blots, antibodies directed against the $\mu$-opioid receptor (PC165L) and various $\mathrm{G}$ protein $\alpha$-subunits were purchased from Calbiochem

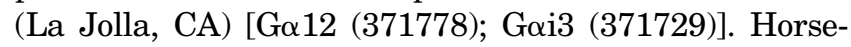
radish peroxidase-labeled secondary antibody was purchased from Amersham (RPN1004) (Arlington Heights, IL). The sources of other agents are published (Xu et al., 2004).

\section{RESULTS \\ Evidence for receptor desensitization and opioid tolerance}

Our first series of experiments determined the effect of chronic DAMGO and HERK on agoniststimulated $\left[{ }^{35} \mathrm{~S}\right]-\mathrm{GTP}-\gamma-\mathrm{S}$ binding. As reported in Table I and Figure 1, both chronic DAMGO and chronic
TABLE I. Effects of DAMGO or HERK pretreatment on agoniststimulated $\left[{ }^{35} \mathrm{~S}\right]-\mathrm{GTP}-\gamma-\mathrm{S}$ binding in the hMOR-CHO cells

\begin{tabular}{lcc}
\hline Agonist & $\begin{array}{c}\text { EC50 } \\
(\mathrm{nM} \pm \mathrm{SD})\end{array}$ & $\begin{array}{c}E_{\mathrm{MAX}} \\
(\% \text { stimulation }\end{array}$ \\
\hline DAMGO & & \\
$\quad$ Control & $12.8 \pm 1.3$ & $230 \pm 4$ \\
DAMGO-pretreated & $73.6 \pm 9.9^{*}$ & $230 \pm 6$ \\
HERK-pretreated & $42.8 \pm 6.5^{*}$ & $140 \pm 4^{*}$ \\
HERK & $92.5 \pm 16.1$ & $259 \pm 9$ \\
Control & $211 \pm 48^{*}$ & $207 \pm 10^{*}$ \\
DAMGO-pretreated & $287 \pm 70^{*}$ & $145 \pm 8^{*}$ \\
HERK-pretreated &
\end{tabular}

The data of three independent experiments were combined and fit to a doseresponse equation. Each parameter value is the mean $\pm \mathrm{SD}(n=3)$. The starisol equation. Each param the marameters unconstrained and then a second time with the parameters constrained to be the same values using the nonlinear least squares curve fitting program MLAB-PC. The $F$-test was used to determine the corresponding p values (compared with control value) for the increase in the sum of squares that resulted from constraint.

$* P<0.01$ when compared to control.

HERK increased the $\mathrm{EC}_{50}$ value of DAMGO from 12.8 to $73.6 \mathrm{nM}$ (5.7-fold) and $42.8 \mathrm{nM}$ (3.3-fold), respectively. Similarly, both chronic DAMGO and chronic HERK increased the $\mathrm{EC}_{50}$ of HERK-stimulated $\left[{ }^{35} \mathrm{~S}\right]-$ GTP- $\gamma$-S binding by 2.3 -fold and 3.1-fold, respectively. Chronic HERK decreased the $E_{\mathrm{MAx}}$ value for both DAMGO- and HERK-stimulated $\left[{ }^{35} \mathrm{~S}\right]-\mathrm{GTP}-\gamma-\mathrm{S}$ binding, reflecting the fact that chronic HERK increased basal $\left[{ }^{35} \mathrm{~S}\right]-\mathrm{GTP}-\boldsymbol{\gamma}-\mathrm{S}$ binding (Fig. 2), an observation that will be presented in greater detail in the next section. The $\left.{ }^{35} \mathrm{~S}\right]-\mathrm{GTP}-\gamma-\mathrm{S}$ binding dose-response data suggest that both chronic DAMGO and chronic HERK produce auto- and cross-tolerance to opioid agonists.

Previous work established that $\left[{ }^{35} \mathrm{~S}\right]-\mathrm{GTP}-\gamma-\mathrm{S}$ binds to two sites, a high affinity agonist-responsive binding site and a low affinity agonist-nonresponsive binding site, and that $\mu$-agonists normally increase the $B_{\mathrm{MAX}}$ of the high affinity site, an effect prevented by chronic morphine treatment (Xu et al., 2003). In this study we determined the effect of chronic DAMGO and HERK on DAMGO-stimulated high affinity agonist-responsive binding. As reported in Table II, in control cells DAMGO $(10 \mu \mathrm{M})$ increased the $B_{\mathrm{MAX}}$ of the high affinity site by $\sim 2$ to 3 fold and also lowered the $K_{\mathrm{d}}$ value. Chronic treatment with HERK significantly increased the basal $B_{\text {MAX }}$ value (3.2-fold). Chronic DAMGO also increased the $B_{\mathrm{MAX}}$, but the magnitude of the effect was too small to become statistically significant. Note that similar results were observed when basal $\left[{ }^{35} \mathrm{~S}\right]-$ GTP- $\gamma$-S binding was measured with a single concentration of radioligand (Fig. 3). After chronic HERK, DAMGO lost the ability to increase the high affinity $\left[{ }^{35} \mathrm{~S}\right]-G T P-\gamma-\mathrm{S}$ binding $B_{\mathrm{MAX}}$. This is likely due to a "ceiling effect," since chronic HERK alone increased the basal $B_{\mathrm{MAX}}$. After chronic DAMGO treatment, DAMGO increased the $B_{\mathrm{MAX}}$ to almost the same level as observed in the control cells, but the increased binding as compared with basal was not statistically 
A. DAMGO

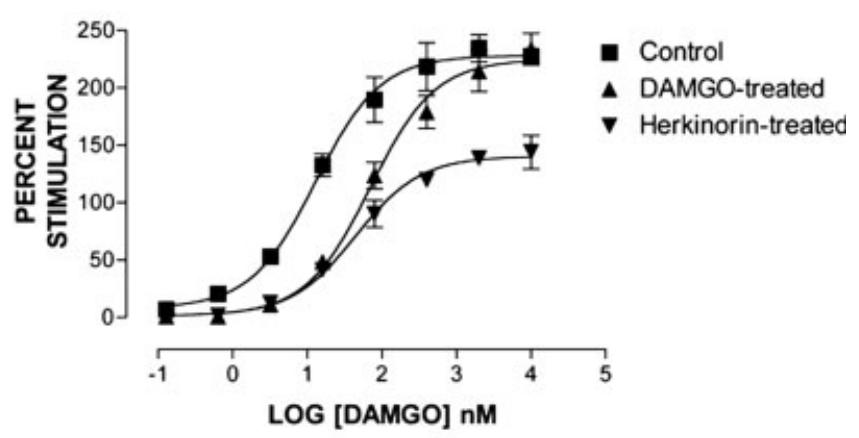

B. HERK

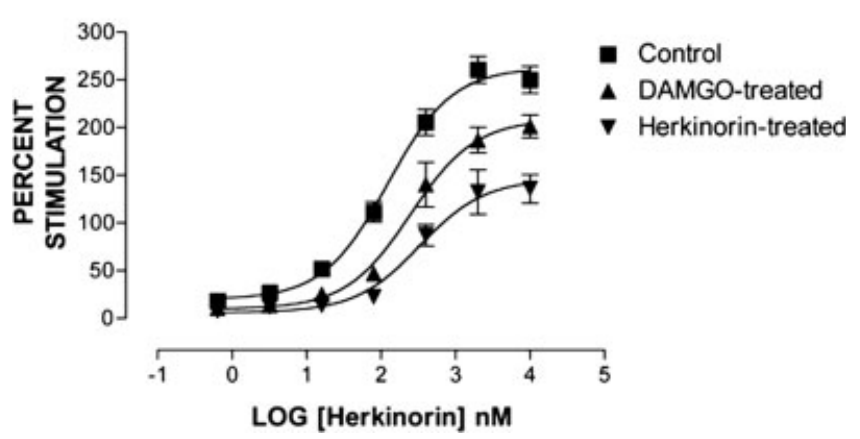

Fig. 1. Drug-stimulated $\left[{ }^{35} \mathrm{~S}\right]-\mathrm{GTP}-\gamma-\mathrm{S}$ binding in hMOR-CHO cells. A. DAMGO dose-response curves were generated using membranes prepared from hMOR-CHO cells after $20 \mathrm{~h}$ treatment with DAMGO $(10 \mu \mathrm{M})$, HERK $(10 \mu \mathrm{M})$ or medium. The data were pooled and analyzed for the best-fit estimates of the $E_{\mathrm{MAX}}$ and $\mathrm{ED}_{50}$ (Table I). Each value is \pm SEM $(n=3)$. B. HERK dose-response curves were generated using membranes prepared from hMOR-CHO cells after $20 \mathrm{~h}$ treatment with DAMGO $(10 \mu \mathrm{M})$, HERK $(10 \mu \mathrm{M})$ or medium. The data were pooled and analyzed for the best-fit estimates of the $E_{\text {MAX }}$ and $\operatorname{ED}_{50}$ (Table I). Each value is $\pm \operatorname{SEM}(n=3)$.

significant because of the somewhat higher basal binding produced by the chronic DAMGO treatment. These data indicate that both chronic HERK and chronic DAMGO desensitize the $\mu$-opioid receptor, since both treatments block the ability of DAMGO to increase the $B_{\mathrm{MAX}}$, an effect that occurs with sensitized $\mu$-receptors.

Our next series of experiments tested for the development of opioid tolerance using the cAMP assay. As demonstrated in Figure 2 and Table III, chronic DAMGO increased the $\mathrm{EC}_{50}$ values of both DAMGO (3.2-fold) and HERK (4.8-fold) for inhibiting forskolinstimulated cAMP accumulation. Chronic HERK eliminated the ability of both DAMGO and HERK to inhibit forskolin-stimulated cAMP, reflecting the fact that chronic HERK reduced forskolin-stimulated cAMP accumulation by $60 \%$ (Fig. 4 ). The cAMP doseresponse data suggest that chronic DAMGO produces auto- and cross-tolerance to opioid agonists. As will be discussed in the next section, the ability of chronic HERK to produce opioid tolerance in the cAMP assay

\section{A. DAMGO}

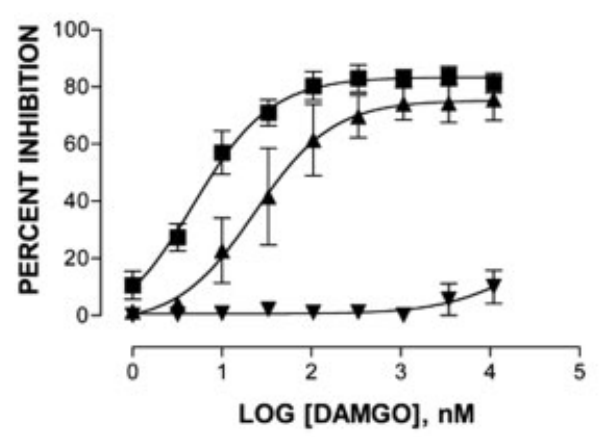

Control

- DAMGO-treated

v HERK-treated

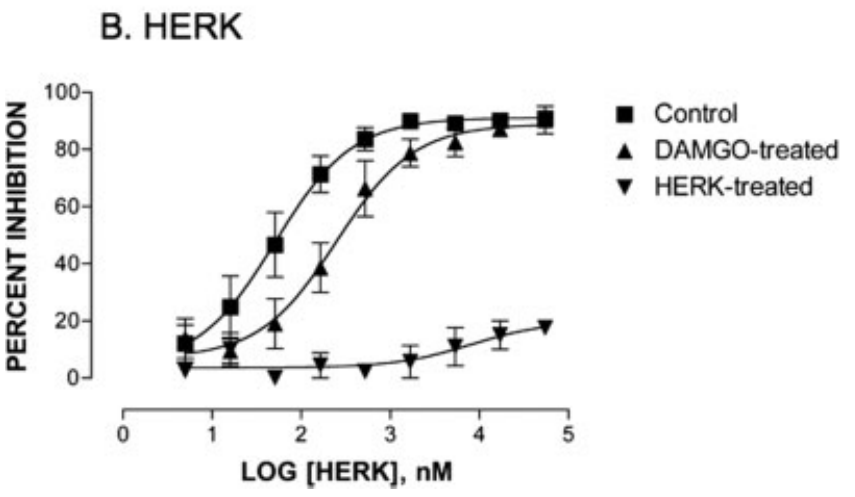

Fig. 2. Drug-inhibition of forskolin-stimulated cAMP accumulation. A. DAMGO dose-response curves were generated using membranes prepared from hMOR-CHO cells after $20 \mathrm{~h}$ treatment with DAMGO $(10 \mu \mathrm{M})$, HERK $(10 \mu \mathrm{M})$ or medium. The data were analyzed for the best-fit estimates of the $E_{\mathrm{MAx}}$ and $\mathrm{ED}_{50}$ (Table III). Each value is \pm SEM $(n=3)$. B. HERK dose-response curves were generated using membranes prepared from hMOR-CHO cells after $20 \mathrm{~h}$ treatment with DAMGO $(10 \mu \mathrm{M})$, HERK $(10 \mu \mathrm{M})$ or medium. The data were analyzed for the best-fit estimates of the $E_{\mathrm{MAX}}$ and $\mathrm{ED}_{50}$ (Table III). Each value is $\pm \operatorname{SEM}(n=3)$.

cannot be directly determined because it produces a constitutively $\mu$-receptor.

\section{Evidence for the generation of constitutively active $\mu$-receptors}

Chronic morphine treatment can generate a constitutively active $\mu$-receptor, the activity of which is detected by an increase in basal $\left[{ }^{35} \mathrm{~S}\right]-\mathrm{GTP}-\gamma-\mathrm{S}$ binding and the increased activity can be reversed by certain antagonists (Sadee et al., 2005; Xu et al., 2003). Chronic HERK, but not DAMGO, increased the basal $\left[{ }^{35} \mathrm{~S}\right]-$ GTP- $\gamma-\mathrm{S}$ binding by about $40 \%$ (Fig. 3). The addition of naloxone $(10 \mu \mathrm{M})$ and CTAP $(10 \mu \mathrm{M})$ to membranes prepared from HERK-treated hMORCHO cells decreased the elevated basal $\left[{ }^{35} \mathrm{~S}\right]-\mathrm{GTP}-\gamma-\mathrm{S}$ binding to less than control levels. The addition of naloxone to membranes prepared from DAMGO-treated hMOR-CHO cells also decreased the basal $\left.{ }^{35} \mathrm{~S}\right]-\mathrm{GTP}-\gamma-$ $\mathrm{S}$ binding by about $20 \%$. As mentioned in the prior section, chronic HERK decreases forskolin-stimulated cAMP accumulation by about $60 \%$ (Fig. 4). This inhibi- 
TABLE II. Effects of DAMGO or HERK pretreatment on basal and DAMGO-stimulated $\left.{ }^{35} \mathrm{~S}\right] G T P-\gamma-S$ binding to the high affinity agonist-responsive $\left[{ }^{35} S\right]-G T P-\gamma-S$ binding site

\begin{tabular}{lccccc}
\hline & \multicolumn{2}{c}{ Control cells } & & \multicolumn{2}{c}{ DAMGO- or HERK-treated cells } \\
\cline { 2 - 3 } \cline { 5 - 6 } High affinity binding site parameters & Basal & DAMGO $(10 \mu \mathrm{M})$ & & Basal & DAMGO $(10 \mu \mathrm{M})$ \\
\hline DAMGO pretreatment & & & & \\
$B_{\max }(\mathrm{fmol} / \mathrm{mg}$ protein $)$ & $1146 \pm 698$ & $3937 \pm 849^{*}$ & & $2122 \pm 869$ & $3963 \pm 716$ \\
$K_{\mathrm{d}}(\mathrm{nM})$ & $15.6 \pm 7.6$ & $7.63 \pm 1.4$ & & $19.9 \pm 6.2$ & $7.71 \pm 1.2^{* *}$ \\
$B_{\text {max }}$ (fmolm/mg protein) & $980 \pm 408$ & $2102 \pm 297^{*}$ & & $3217 \pm 791^{\#}$ & $2371 \pm 322$ \\
$K_{\mathrm{d}}(\mathrm{nM})$ & $10.0 \pm 3.4$ & $4.61 \pm 0.6^{*}$ & & $18.6 \pm 3.5$ & $5.02 \pm 0.6^{* *}$ \\
\hline
\end{tabular}

The data of three independent experiments were combined ( 240 data points). The data were analyzed as described in Methods for the best-fit parameter estimates ( $\pm \mathrm{SD}$ ) of the high affinity $B_{\max }$ and $K_{\mathrm{d}}$. Statistical significance for the $B_{\max }$ and $K_{\mathrm{d}}$ were determined by simultaneously fitting the data to the two-site model first with the parameters unconstrained and then a second time with the parameters constrained to be the same values. The $F$-test was used to determine the corresponding $P$-values for the increase in the sum of squares that resulted from the constraint.

$* P<0.05$ when compared to the basal value.

${ }^{*} P<0.01$ when compared to basal value.

${ }^{\#} P<0.05$ when compared to the control value.

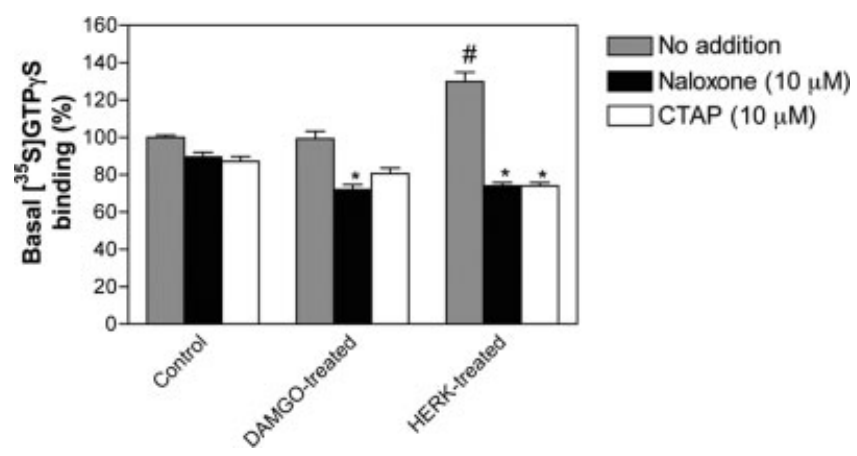

Fig. 3. Comparison of the effects of naloxone $(10 \mu \mathrm{M})$ and CTAP $(10 \mu \mathrm{M})$ on basal $\left[{ }^{35} \mathrm{~S}\right] \mathrm{GTP}-\gamma-\mathrm{S}$ binding in the control or pretreated hMOR-CHO cells. Results are presented as mean \pm SEM $(n=3)$. ${ }^{*} P<0.01$ when compared with no addition group. ${ }^{\#} P<0.01$ when compared with no addition condition of the control cells (two-tailed Student's $t$-test).

TABLE III. Effects of DAMGO or HERK pretreatment on agonist-mediated inhibition of forskolin-stimulated cAMP accumulation in the hMOR-CHO cells

\begin{tabular}{lcc}
\hline Agonist & $\mathrm{EC}_{50}(\mathrm{nM} \pm \mathrm{SEM})$ & $E_{\mathrm{MAX}}(\%$ inhibition $)$ \\
\hline DAMGO & & \\
Control & $3.23 \pm 0.63$ & $86.2 \pm 2.5$ \\
DAMGO-pretreated & $10.4 \pm 1.2^{*}$ & $80.9 \pm 4.3$ \\
HERK-pretreated & flat & flat \\
HERK & $48.7 \pm 13.7$ & $89.0 \pm 2.2$ \\
Control & $235 \pm 85^{*}$ & $82.7 \pm 7.0$ \\
DAMGO-pretreated & flat & flat \\
HERK-pretreated &
\end{tabular}

The $\mathrm{EC}_{50}$ and $E_{\max }$ were determined using the program GraphPad Prism. Each value is the mean $\pm \operatorname{SEM}(n=4)$.

${ }^{*} P<0.05$ when compared to control cells (two-tailed Students $t$-test).

tion is relieved by the addition of $\mu$-receptor antagonists (naloxone or CTAP), strongly supporting the hypothesis that chronic HERK generates a constitutively active $\mu$ receptor. Similar findings were observed in human embryonic kidney (HEK) cells expressing the cloned human $\mu$-receptor (data not shown).

\section{Evidence for the generation of cAMP superactivation}

It is well known that chronic morphine treatment up-regulates the cAMP system, an effect commonly

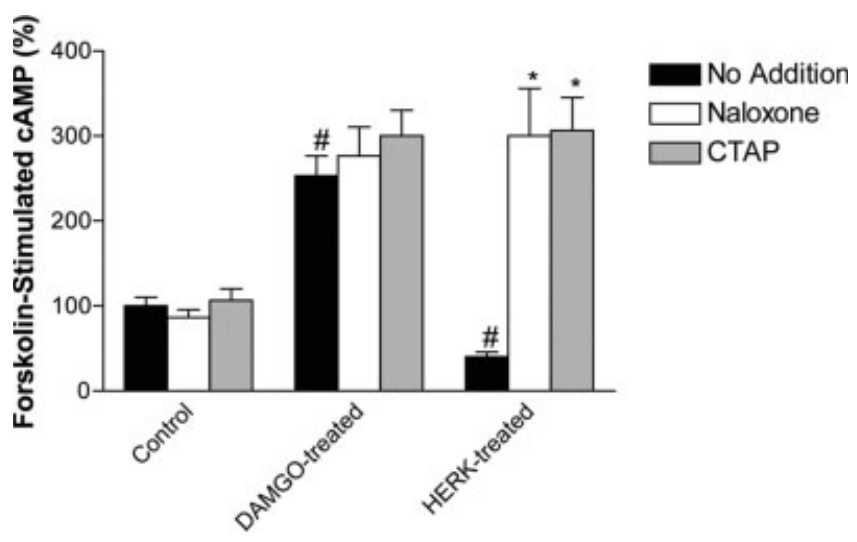

Fig. 4. Comparison of the effects of naloxone $(10 \mu \mathrm{M})$ and CTAP $(10 \mu \mathrm{M})$ on forskolin-stimulated cAMP accumulation in the control or pretreated hMOR-CHO cells. Results are presented as mean \pm SEM $(n=3) .{ }^{*} P<0.01$ when compared with no addition group. ${ }^{\#} P$ $<0.01$ when compared with no addition condition of the control cells (two-tailed Student's $t$-test).

termed cAMP superactivation (Waldhoer et al., 2004). This effect, commonly accepted to be a cellular marker for dependence (Nestler and Aghajanian, 1997), is readily detected by an increase in the forskolinstimulated cAMP accumulation. As demonstrated in Figure 4, chronic DAMGO increased forskolin-stimulated cAMP by about 2.5-fold. Although chronic HERK decreased forskolin-stimulated cAMP, the addition of antagonists to inhibit the constitutively active receptors, resulted in cAMP accumulation similar to that seen after chronic DAMGO. These data indicate that both HERK and DAMGO produce cAMP superactivation.

\section{Effect of chronic drug treatments on G protein expression}

Our next series of experiments determined the effect of chronic morphine, DAMGO, and HERK on $\mu$-receptor expression. Figure 5A shows the full western blot for the $\mu$-receptor antibody. Probing homogenates prepared from hMOR-CHO cells revealed a $\sim 75 \mathrm{kDA}$ 


\section{A. Western blotting analysis of $\mu$-OR protein in the hMOR-CHO and hDOR-CHO cells \\ B. $\mu-O R$ expression after chronic drug treatment}
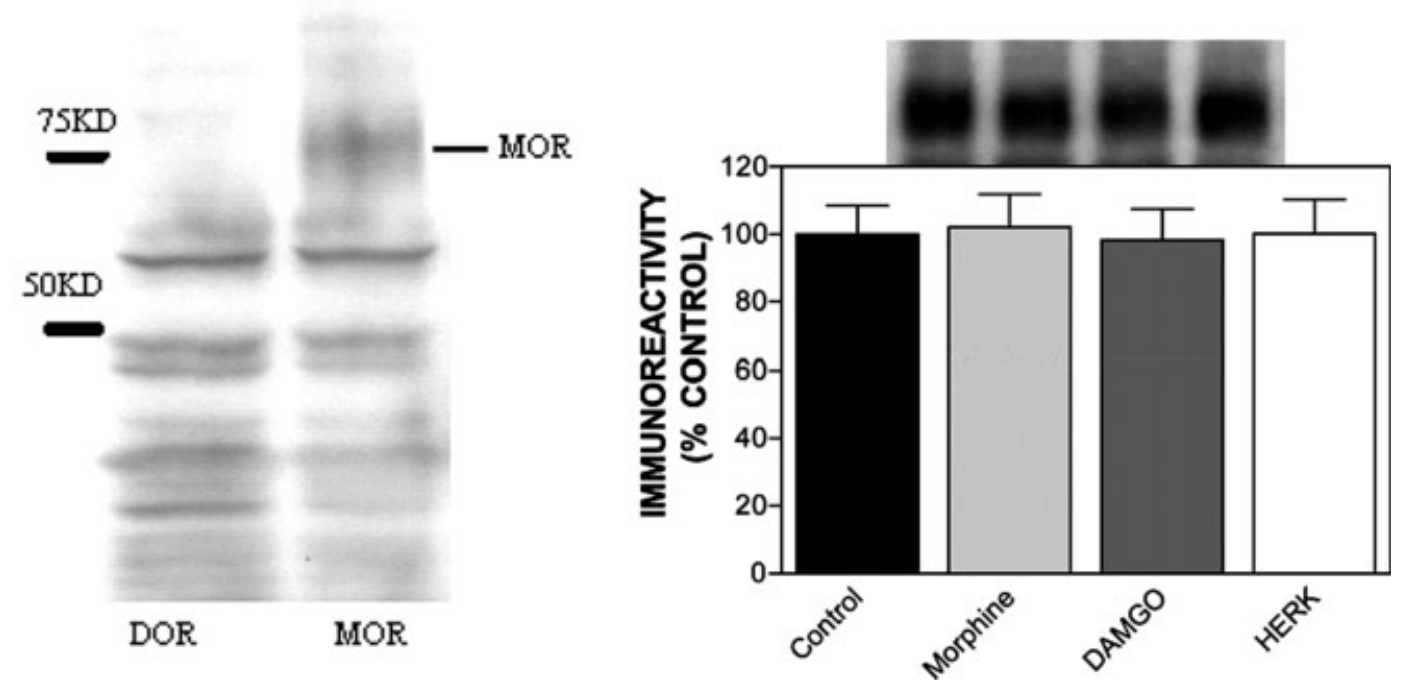

Fig. 5. $\mu$-OR expression. Panel A. Western blotting analysis of $\mu$-OR protein in the control hMOR-CHO and hDOR-CHO cells. Samples obtained from the control hMOR-CHO or hDOR-CHO cells were prepared as described in Methods section and subjected to Western blot analysis; Panel B. Comparison of the effects of chronic

drug treatment on expression level of $\mu$-OR protein in the hMORCHO cells. Results are expressed as mean \pm SEM $(n=3)$. Representative Western blots are shown. ${ }^{*} P<0.05$ when compared with control cells (two-tailed Student's $t$-test).

\section{A. Gai3 Expression}

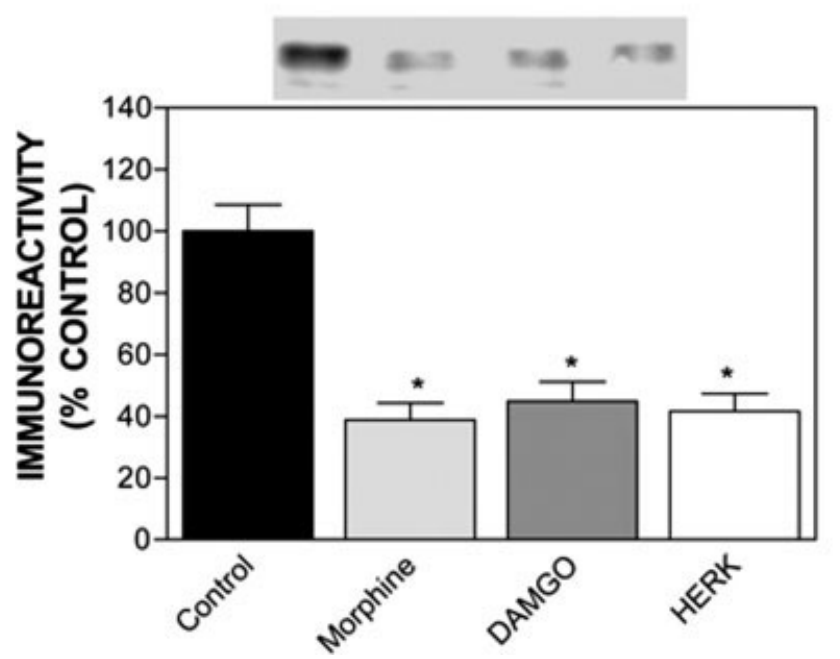

\section{B. G $\alpha 12$ Expression}

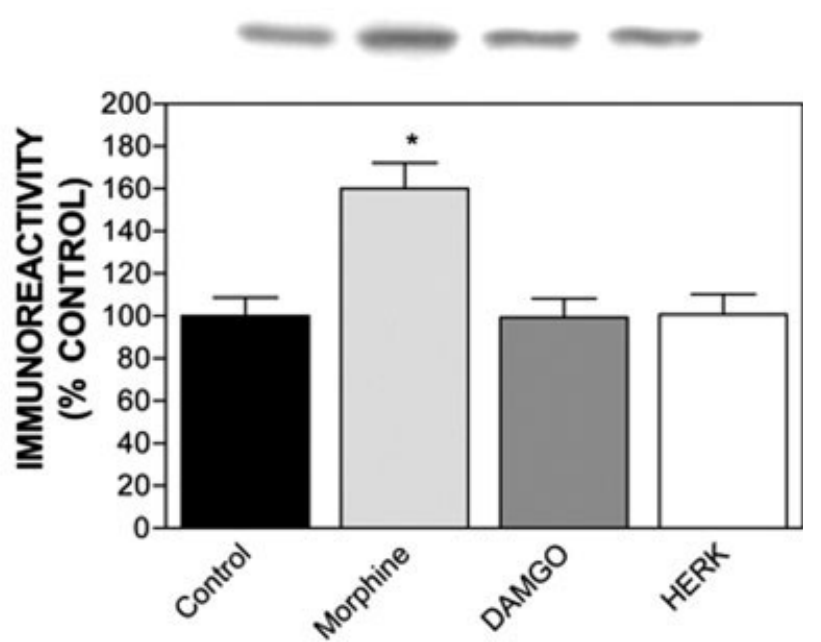

Fig. 6. Comparison of the effects of chronic drug treatment on expression level of $\mathrm{G}_{\alpha_{3}}(\mathbf{A})$ and $\mathrm{G}_{\alpha_{12}}$ (B) proteins in hMOR-CHO cells. Results are expressed as mean \pm SEM $(n=3)$. Representative Western blots are shown. ${ }^{*} P<0.05$ when compared with control cells (two-tailed Student's $t$-test).

band that was not present in homogenates prepared from hDOR-CHO cells, indicating that the $75 \mathrm{kDa}$ band is the $\mu$-opioid receptor. As reported in Figure 5B, chronic morphine, DAMGO, and HERK failed to alter the level of $\mu$-receptor expression, indicating that these chronic treatments do not induce receptor downregulation. As reported previously (Xu et al., 2005), chronic treatment with all three $\mu$-agonists (morphine, DAMGO, HERK) down-regulated $\mathrm{G}_{\mathrm{i} 3}$ (Fig. 6A). It is Interesting to see only chronic morphine, but not 
DAMGO and HERK, up-regulated $\mathrm{G}_{\alpha 12}$ expression (Fig. 6B).

\section{DISCUSSION}

The mechanisms that underlie the development of tolerance and dependence to opioid drugs have been studied for many decades, and involve changes at the cellular, synaptic, and systems level (Williams et al., 2001). $\mu$-Opioid receptors, like other $G$ protein coupled receptors (GPCR) undergo a process of agonist-induced homologous desensitization, which includes agonistinduced phosphorylation of the receptor by GPCR kinases (GRKs), recruitment of $\beta$-arrestin, followed by internalization. The binding of $\beta$-arrestin to the receptor blocks further activation of $\mathrm{G}$ proteins by agonist, thus producing a desensitized receptor (For review see: (Gainetdinov et al., 2004). Once internalized, $\mu$-receptors can either be recycled back to the cell membrane, or degraded via lysozomes. The recycling hypothesis is now thought to provide a mechanism to recycle re-sensitized receptors (Koch et al., 2005), as predicted by Roth et al. (1998). According to this model, $\mu$-agonists that promote internalization (internalizing agonists) produce less tolerance because the recycling of receptors replaces desensitized receptors with receptors ready for activation by agonist. On the other hand, noninternalizing agonists, such as morphine, allow the accumulation of desensitized receptors and the development of tolerance.

A simplistic prediction of this model is that internalizing and noninternalizing $\mu$-opioid agonists will produce significantly different cellular changes, such as markedly different levels of $\mu$-receptor desensitization. To test this hypothesis, we compared the cellular changes produced by DAMGO, an opioid agonist well known to robustly promote receptor internalization (Finn and Whistler, 2001; Koch et al., 2005), and HERK, a recently described analog of Salvinorin A. HERK is a fully efficacious $\mu$-agonist with a binding $\mathrm{Ki}$ for the $\mu$-receptor of $16 \mathrm{nM}$ (vs. $5.0 \mathrm{nM}$ for DAMGO) (Harding et al., 2005). Importantly, Bohn et al. (2000) reported that unlike morphine, the HERK-bound $\mu$-opioid receptor does not internalize or recruit Barr2-GFP in HEK-293 cells and that this cannot be overcome by overexpressing GRK2 or by substituting the $\mu$ OR1-D splice variant. The $\mu$ OR1-D is a naturally occurring splice variant of the mouse $\mu$ opioid receptor that differs from the $\mu$-opioid receptor only in the C-terminal sequence and has been shown to recruit $\beta$ arr2-GFP and internalize following morphine treatment. Thus, HERK is an ideal noninternalizing $\mu$-agonist to compare to DAMGO.

Opioid tolerance and receptor desensitization is readily assessed with the $\left[{ }^{35} \mathrm{~S}\right]-\mathrm{GTP}-\gamma-\mathrm{S}$ binding assay. Chronic treatment of hMOR-CHO cells with either DAMGO or HERK produced auto- and cross-tolerance, as determined by DAMGO- and HERK-stimulated $\left[{ }^{35} \mathrm{~S}\right]$-GTP- $\gamma-\mathrm{S}$ binding. The dose-response curves indicated that both agents desensitize the $\mu$-receptor. The decreased $E_{\text {MAX }}$ value observed after HERK-treatment was due to an increased level of basal $\left[{ }^{35} \mathrm{~S}\right]-\mathrm{GTP}-\gamma-\mathrm{S}$ binding, an observation supportive of the presence of constitutively active $\mu$-receptors.

$\left[{ }^{35} \mathrm{~S}\right]-\mathrm{GTP}-\gamma-\mathrm{S}$ binds to two sites, a high affinity agonist-responsive binding site and a low affinity agonist-nonresponsive binding site. $\mu$-Agonists normally increase the $B_{\text {MAX }}$ of the high affinity site, an effect prevented by chronic morphine treatment (Xu et al., 2003). In membrane preparation containing sensitized receptors, $\mu$-agonists increase the $B_{\mathrm{MAX}}$ of the high affinity $\left[{ }^{35} \mathrm{~S}\right]-\mathrm{GTP}-\gamma-\mathrm{S}$ binding site by promoting the dissociation of GDP prebound to G proteins, thereby increasing the number of binding sites available for labeling with $\left[{ }^{35} \mathrm{~S}\right]-\mathrm{GTP}-\gamma-\mathrm{S}$. Thus, the blunting of the ability of an agonist to increase the $B_{\mathrm{MAX}}$ of the high affinity site marks the presence of desensitized receptors. As reported in Table II, both chronic HERK and DAMGO treatments attenuated the ability of DAMGO to increase the $B_{\text {MAX }}$ of the high affinity $\left[{ }^{35} \mathrm{~S}\right]-G T P-\gamma-S$ binding site higher than the baseline $B_{\mathrm{MAX}}$ value. This effect was most apparent after chronic HERK treatment. After chronic DAMGO treatment, DAMGO failed to produce a statistically significant increase in the $B_{\text {MAX }}$ value as compared with baseline, perhaps because the baseline $B_{\mathrm{MAX}}$ in DAMGO-treated cells was higher than seen in control cells. These data provide evidence that both chronic HERK and DAMGO treatment desensitize the $\mu$-receptor.

Chronic treatment of cells with either DAMGO or HERK changes the mechanism by which agonists stimulate $\left.{ }^{35} \mathrm{~S}\right]-\mathrm{GTP}-\gamma-\mathrm{S}$ binding. In control cells, agonists stimulate $\left[{ }^{35} \mathrm{~S}\right]-\mathrm{GTP}-\gamma-\mathrm{S}$ binding primarily by increasing the $B_{\mathrm{MAX}}$ and also by decreasing the $K_{\mathrm{d}}$. After chronic drug treatment, agonists stimulate $\left[{ }^{35} \mathrm{~S}\right]-\mathrm{GTP}-\gamma-\mathrm{S}$ binding only by lowering the $K_{\mathrm{d}}$. Therefore, the ability of agonists to stimulate $\left[{ }^{35} \mathrm{~S}\right]-\mathrm{GTP}-\gamma-\mathrm{S}$ binding after chronic HERK or DAMGO, as shown in Figure 1, results primarily from its decreasing the $K_{\mathrm{d}}$ of the high affinity agonist-responsive $\left[{ }^{35} \mathrm{~S}\right]-\mathrm{GTP}-\gamma-\mathrm{S}$ binding site. The decreased $E_{\mathrm{MAX}}$ of HERK following chronic DAMGO treatment (207\% vs. 259\%) likely indicates that HERK cannot decrease the $K_{\mathrm{d}}$ of the high affinity agonist-responsive $\left[{ }^{35} \mathrm{~S}\right]-\mathrm{GTP}-\gamma-\mathrm{S}$ binding site enough to produce the same degree of overall stimulation as observed in control cells.

Opioid agonists inhibit forskolin-stimulated cAMP accumulation in intact cells, providing a well-established assay to determine the effect of chronic drug treatment on the development of tolerance. Chronic DAMGO treatment produced tolerance to both DAMGO and HERK, as evidenced by 3 - to 4 -fold shifts to the right in the dose-response curves. Chronic DAMGO did not significantly change the maximal 
degree of inhibition ( $\left.E_{\mathrm{MAX}}\right)$. Chronic HERK treatment eliminated the ability of either DAMGO or HERK to further inhibit forskolin-stimulated cAMP. From a pharmacological perspective, this represents the development of "complete" tolerance. The mechanism underlying this effect is HERK-induced formation of constitutively active $\mu$-receptors (Sadee et al., 2005). Evidence supporting this includes the fact that chronic-HERK increased basal $\left[{ }^{35} \mathrm{~S}\right]-\mathrm{GTP}-\gamma-\mathrm{S}$ binding, an effect reversed by the addition of antagonists as shown in Figure 3 (Wang et al., 2001), that chronic HERK increased the basal $B_{\text {MAX }}$ of the high affinity agonist-responsive [ $\left.{ }^{35} \mathrm{~S}\right]-\mathrm{GTP}-\gamma-\mathrm{S}$ binding site (Table II), and that chronic HERK reduced forskolin-stimulated cAMP accumulation by about $60 \%$ (Fig. 2). This latter observation simply indicates that the constitutively active $\mu$-receptor substantially inhibits adenylate cyclase activity, thereby reducing the ability of forskolin to stimulate cAMP accumulation.

Both chronic DAMGO and chronic HERK produced cAMP superactivation, an effect we observed by measuring the magnitude of forskolin-stimulated cAMP accumulation. Our findings support those of Zhao et al. (2006), who reported, contrary to the "RAVE" hypothesis (He and Whistler, 2005), that the ability of a $\mu$-agonist to promote internalization of $\mu$-receptors does not correlate with the ability of the agonist to produce cAMP superactivation. Although chronic HERK decreased forskolin-stimulated cAMP, the addition of antagonists to inhibit the constitutively active receptors, resulted in marked increase in cAMP accumulation similar to that seen after chronic DAMGO. These data indicate that both HERK and DAMGO produce cAMP superactivation.

Our data indicate that both internalizing and noninternalizing $\mu$-agonists produce opioid tolerance, receptor desensitization and up-regulation of the cAMP system. The major difference we observed between the two types of $\mu$-agonists is that chronic HERK induced the formation of constitutively active $\mu$-receptors to a profound degree. We assume that the development of cAMP superactivation predicts the propensity of an agonist to produce dependence in vivo, our results indicate that DAMGO and HERK would produce similar degrees of dependence, but that the dose of naloxone required to trigger withdrawal would be lower in animals chronically treated with HERK, than with DAMGO.

Importantly, it is perhaps overly ambitious to predict the in vivo effects of noninternalizing and internalizing $\mu$-agonists based on studies conducted with cultured cells. Cell-based studies are useful for dissecting general mechanisms of receptor regulation, but the details of such regulation will likely change as a function of cell type and tissue, and their corresponding repertoire of regulatory elements. For example, morphine does not promote $\mu$-receptor internalization in cultured cells, except when GRKs are over-expressed (Whistler and von Zastrow, 1998; Zhang et al., 1998). However, in striatal neurons, morphine produces robust internalization (Haberstock-Debic et al., 2005), indicating that generalizations made on the basis of a study with a particular cell line do not necessarily extrapolate directly to the in vivo situation.

Similarly, some authors have used "agonist relative activity in cAMP assay vs. endocytosis (RAVE) values to predict that $\mu$-agonists that promote endocytosis will have a reduced propensity to produce tolerance and dependence in whole organisms (He and Whistler, 2005). Both in vitro (Zhao et al., 2006) and in vivo data appears to contradict this hypothesis. For example, it is well known that DAMGO (RAVE value $\sim 1$ ) administration produces robust tolerance and dependence in the rat (Maldonado et al., 1990). Chronic methadone (RAVE value $\sim 1$ ) treatment produces a robust withdrawal syndrome (Dougherty et al., 1987; Ling et al., 1984), the intensity of which could be influenced by the ability of D-methadone to antagonize N-methyl-D-aspartate glutamate receptors (Davis and Inturrisi, 1999). Sufentanil, which has a RAVE value of $\sim 1$ (Koch et al., 2005), produces a similar degree of tolerance as observed for morphine (RAVE value 10) (Kissin et al., 1991; Stevens and Yaksh, 1989b), and chronic morphine and sufentanil administration produced similar degrees of dependence (Stevens and Yaksh, 1989a).

In summary, chronic treatment of hMOR-CHO cells with both internalizing and noninternalizing $\mu$-agonists produces tolerance, receptor desensitization and up-regulation of the cAMP system. The major difference between the two types of $\mu$-agonists is that chronic HERK induced the formation of constitutively active $\mu$-receptors to a profound degree. Consistent with the data in cAMP assay, chronic DAMGO or HERK decreased the expression of Gai3 ( 60\%), suggesting that down-regluation of $\mathrm{G}$ protein subunits (Goi3) may contribute to opioid tolerance. Further research will test if naloxone or CTAP can block chronic DAMGO or chronic HERK-induced down-regulation of Goi3. Viewed collectively with published data, our data indicate that both internalizing and noninternalizing $\mu$-agonists produce cellular signs of tolerance and dependence in hMOR-CHO cells after chronic treatment and that this effect was associated with an increase in adenylyl cyclase activity.

\section{REFERENCES}

Bohn LM, Gainetdinov RR, Lin FT, Lefkowitz RJ, Caron MG. 2000. Mu-Opioid receptor desensitization by $\beta$-arrestin-2 determines morphine tolerance but not dependence. Nature 408:720-723.

Davis AM, Inturrisi CE. 1999. D-Methadone blocks morphine tolerance and $N$-methyl-D-aspartate-induced hyperalgesia. J Pharmacol Exp Ther 289:1048-1053.

Dougherty PM, Pearl J, Krajewski KJ, Pellis NR, Dafny N. 1987. Differential modification of morphine and methadone dependence by interferon $\alpha$. Neuropharmacology 26:1595-1600. 
Finn AK, Whistler JL. 2001. Endocytosis of the mu opioid receptor reduces tolerance and a cellular hallmark of opiate withdrawal. Neuron 32:829-839.

Gainetdinov RR, Premont RT, Bohn LM, Lefkowitz RJ, Caron MG. 2004. Desensitization of G-protein-coupled receptors and neuronal functions. Annu Rev Neurosci 27:107-144.

Gintzler AR, Chakrabarti S. 2000. Opioid tolerance and the emergence of new opioid receptor-coupled signaling. Mol Neurobiol 21: 21-33.

Groer CE, Tidgewell K, Mover RA, Harding WW, Rothman RB, Prisinzano TE, Bohn LM. 2006. An opioid agonist that does not induce mu opioid receptor-arrestin interactions or receptor internalization. Mol Pharmacol 2006 Nov 7, [Epub ahead of print].

Haberstock-Debic H, Kim KA, Yu YJ, von Zastrow M. 2005. Morphine promotes rapid, arrestin-dependent endocytosis of muopioid receptors in striatal neurons. J Neurosci 25:7847-7857.

Harding WW, Tidgewell K, Byrd N, Cobb H, Dersch CM, Butelman ER, Rothman RB, Prisinzano TE. 2005. Neoclerodane diterpenes as a novel scaffold for mu opioid receptor ligands. J Med Chem 48:4765-4771.

He L, Whistler JL. 2005. An opiate cocktail that reduces morphine tolerance and dependence. Curr Biol 15:1028-1033.

Heyliger SO, Ni Q, Rothman RB. 2000. Resolution of two $\left[{ }^{35} \mathrm{~S}\right] \mathrm{GTP}-$ $\gamma-\mathrm{S}$ binding sites and their response to chronic morphine treatment: A binding surface analysis. Brain Res Bull 51:357-362.

Kissin I, Brown PT, Bradley EL Jr. 1991. Magnitude of acute tolerance to opioids is not related to their potency. Anesthesiology 75:813-816.

Koch T, Widera A, Bartzsch K, Schulz S, Brandenburg LO, Wundrack N, Beyer A, Grecksch G, Hollt V. 2005. Receptor endocytosis counteracts the development of opioid tolerance. Mol Pharmacol 67:280-287.

Law PY, Loh HH, Wei LN. 2004. Insights into the receptor transcription and signaling: Implications in opioid tolerance and dependence. Neuropharmacology 47(Suppl 1):300-311.

Ling GS, Tappe NS, Inturrisi CE. 1984. Methadone induced physical dependence in the rat. Life Sci 34:683-690.

Maldonado R, Feger J, Fournie-Zaluski MC, Roques BP. 1990. Differences in physical dependence induced by selective mu or delta opioid agonists and by endogenous enkephalins protected by peptidase inhibitors. Brain Res 520:247-254.

Nestler EJ, Aghajanian GK. 1997. Molecular and cellular basis of addiction. Science 278:58-63.

Roth BL, Willins DL, Kroeze WK. 1998. G-protein-coupled receptor (GPCR) trafficking in the central nervous system: Relevance for drugs of abuse. Drug Alcohol Depend 51:73-85.

Rothman RB. 1992. A review of the role of anti-opioid peptides in morphine tolerance and dependence. Synapse 12:129-138.

Rothman RB, Reid AA, Mahboubi A, Kim C-H, de Costa BR, Jacobson AE, Rice KC. 1991. Labeling by $\left[{ }^{3} \mathrm{H}\right] 1,3-\mathrm{Di}(2$-tolyl)guanidine of two high affinity binding sites in guinea pig brain: Evidence for allosteric regulation by calcium channel antagonists and pseudoallosteric modulation by $\sigma$ ligands. Mol Pharmacol 39:222-232.

Sadee W, Wang D, Bilsky EJ. 2005. Basal opioid receptor activity, neutral antagonists, and therapeutic opportunities. Life Sci 76 : 1427-1437.
Simonin F, Schmitt M, Laulin JP, Laboureyras E, Jhamandas JH, MacTavish D, Matifas A, Mollereau C, Laurent P, Parmentier M, Kieffer BL, Bourguignon JJ, Simonnet G. 2006. RF9, a potent and selective neuropeptide FF receptor antagonist, prevents opioidinduced tolerance associated with hyperalgesia. Proc Natl Acad Sci USA 103:466-471.

Standifer KM, Pasternak GW. 1997. G-proteins and opioid receptormediated signalling. Cell Signal 9:237-248.

Stevens CW, Yaksh TL. 1989a. Magnitude of opioid dependence after continuous intrathecal infusion of mu- and delta-selective opioids in the rat. Eur J Pharmacol 166:467-472.

Stevens CW, Yaksh TL. 1989b. Time course characteristics of tolerance development to continuously infused antinociceptive agents in rat spinal cord. J Pharmacol Exp Ther 251:216-223.

Waldhoer M, Bartlett SE, Whistler JL. 2004. Opioid receptors. Annu Rev Biochem 73:953-990.

Wang D, Raehal KM, Bilsky EJ, Sadee W. 2001. Inverse agonists and neutral antagonists at mu opioid receptor (MOR): Possible role of basal receptor signaling in narcotic dependence. J Neurochem 77:1590-1600.

Wang Y, Li JG, Huang P, Xu W, Liu-Chen LY, 2003. Differential effects of agonists on adenylyl cyclase superactivation mediated by the $\kappa$ opioid receptors: Adenylyl cyclase superactivation is independent of agonist-induced phosphorylation, desensitization, internalization, and down-regulation. J Pharmacol Exp Ther 307:11271134.

Whistler JL, von Zastrow M. 1998. Morphine-activated opioid receptors elude desensitization by $\beta$-arrestin. Proc Natl Acad Sci USA 95:9914-9919.

Williams JT, Christie MJ, Manzoni O. 2001. Cellular and synaptic adaptations mediating opioid dependence. Physiol Rev 81:299343.

$\mathrm{Xu} \mathrm{H}$, Hashimoto A, Rice KC, Jacobson AE, Thomas JB, Carroll FI, Lai J, Rothman RB. 2001. Opioid peptide receptor studies. 14. Stereochemistry determines agonist efficacy and intrinsic efficacy in the $\left[{ }^{35} \mathrm{~S}\right] \mathrm{GTP}-\gamma-\mathrm{S}$ functional binding assay. Synapse 39:64-69.

$\mathrm{Xu} \mathrm{H}$, Lu YF, Rothman RB. 2003. Opioid peptide receptor studies. 16. Chronic morphine alters G-protein function in cells expressing the cloned mu opioid receptor. Synapse 47:1-9.

Xu H, Wang X, Wang J, Rothman RB. 2004. Opioid peptide receptor studies. 17. Attenuation of chronic morphine effects after antisense oligodeoxynucleotide knock-down of RGS9 protein in cells expressing the cloned mu opioid receptor. Synapse 52:209-217.

Xu H, Wang X, Zimmerman D, Boja ES, Wang J, Bilsky EJ, Rothman RB. 2005. Chronic morphine up-regulates $\mathrm{G}\{\alpha\} 12$ and cytoskeletal proteins in chinese hamster ovary cells expressing the cloned \{micro\} opioid receptor. J Pharmacol Exp Ther 315:248255.

Zhang J, Ferguson SS, Barak LS, Bodduluri SR, Laporte SA, Law PY, Caron MG. 1998. Role for G-protein-coupled receptor kinase in agonist-specific regulation of mu-opioid receptor responsiveness. Proc Natl Acad Sci USA 95:7157-7162.

Zhao H, Loh HH, Law PY. 2006. Adenylyl cyclase superactivation induced by long-term treatment with opioid agonist is dependent on receptor localized within lipid rafts and is independent of receptor internalization. Mol Pharmacol 69:1421-1432. 